\title{
Some aspects regarding natural gas and bibliometric networks
}

\author{
Paul Emil Ilea ${ }^{1}$, Dan Săvescu ${ }^{2}$ and Augustin Stoica ${ }^{3}$ \\ ${ }^{1}$ Product Design, Mechatronics and Enviroment Department, Transilvania University of Braov, \\ Braşov, Romania \\ ${ }^{2}$ Product Design, Mechatronics and Enviroment Department, Transilvania University of Braov, \\ Braşov, Romania \\ ${ }^{3}$ Engineering Department, Lucian Blaga University of Sibiu, Sibiu, Romania \\ E-mail: paul.ilea@unitbv.ro
}

\begin{abstract}
In this paper, some aspects about natural gas, natural gas measurement, unauthorized interventions and stopping them were presented. A Scientometric study was conducted by querying the Web of Science database for the field of "natural gas". Based on the data obtained from Web of Science, the bibliometric relays were built using VOSviewer software. Bibliometric networks are useful for establishing the direction of research. The connections created in this software indicate your publications, magazines, researchers, the countries in which it was published, your interest in the subject of "natural gas" depending on the years. Product quality management and risk management proposes the elaboration of a set of procedures through which to design a gas meter that can prevent and reduce unauthorized interventions on gas meters.
\end{abstract}

Keywords: Natural gas, gas meter, Web of Science, VOSviewer, management

\section{Introduction}

All over the world, natural gas distribution companies are trying to make their balance between the gas bought by the company and the one distributed or supplied to consumers more efficient.

This efficiency is achieved through a good maintenance on the entire distribution system, starting from the delivery / reception states, continuing with the distribution network, reaching the regulationmeasurement equipment of the domestic or non-household consumers.

Depending on the legislation in force in each country, the gas losses suffered by a natural gas distribution company are due to leaks in the distribution system, faulty measuring devices or due to unauthorized consumption.[1]

Gas losses or unmetered consumption are called technological consumption, they being managed in Romania by ANRE (National Energy Regulatory Authority) and added to a certain extent to the final price to the consumer.

Unauthorized intervention on a distribution system can be done in two ways, either by bypassing the natural gas measuring device completely, or by direct intervention on it, so that its measurement is not a real one.

The current trend for unauthorized consumption is growing.

According to the ANRE monitoring report in January 2021 in Romania there are 4182330 consumers, of which 3953330 are household consumers, and 229030 are non-household consumers. [2] 
Taking into account the tariff increases for the supply and distribution of natural gas expected this year in Romania and the number of consumers, we can conclude that the gas losses caused by unauthorized interventions in the system represent a significant percentage of the total gas balance.

Distribution operators must train specialists who are able to quickly identify this type of unauthorized intervention and remove it.

Any unauthorized intervention in the natural gas distribution system and implicitly on the measuring devices is a crime and is punishable according to the "Law on Electricity and Natural Gas No. 123/2012". [3]

Interrogating the Web of Science (WOS) database, we conducted a scientometric study that shows that globally, in the period 2001-2021, there are a number of 28462 publications for the subject "natural gas". I could see that this topic is of interest and has an ascending level.

Following the query from Web of Science, the data obtained were processed with the VOSviwer software tool for creating and viewing bibliometric networks.

As well as the following research directions, I propose an improved gas meter, which will prevent and stop unauthorized natural gas consumption.

\section{Literature review}

\subsection{Scientometric study from the Web of Science}

Analyzing the database of Web of Science, we conducted a scientometric study that shows that globally, in the period 2001-2002, there are a number of 28462 publications for the subject "natural gas", in the area of energy fuels, thermodynamics, mechanical engineering, material science multidisciplinary, engineering electrical electronic, mechanics, engineering petroleum, engineering industrial, management, transportation science technology, computer science interdisciplinary applications, automation control systems, engineering manufacturing and computer science software. [4]

Analyzing Figure 1.1, which shows the distribution of publications by year, we find that the trend of this topic is upward, with a peak of publications in 2019 with 2831 publications $(15.347 \%)$ and in $2020(15,299 \%)$ with 2822 publications. This shows that the subject is of great interest for research.

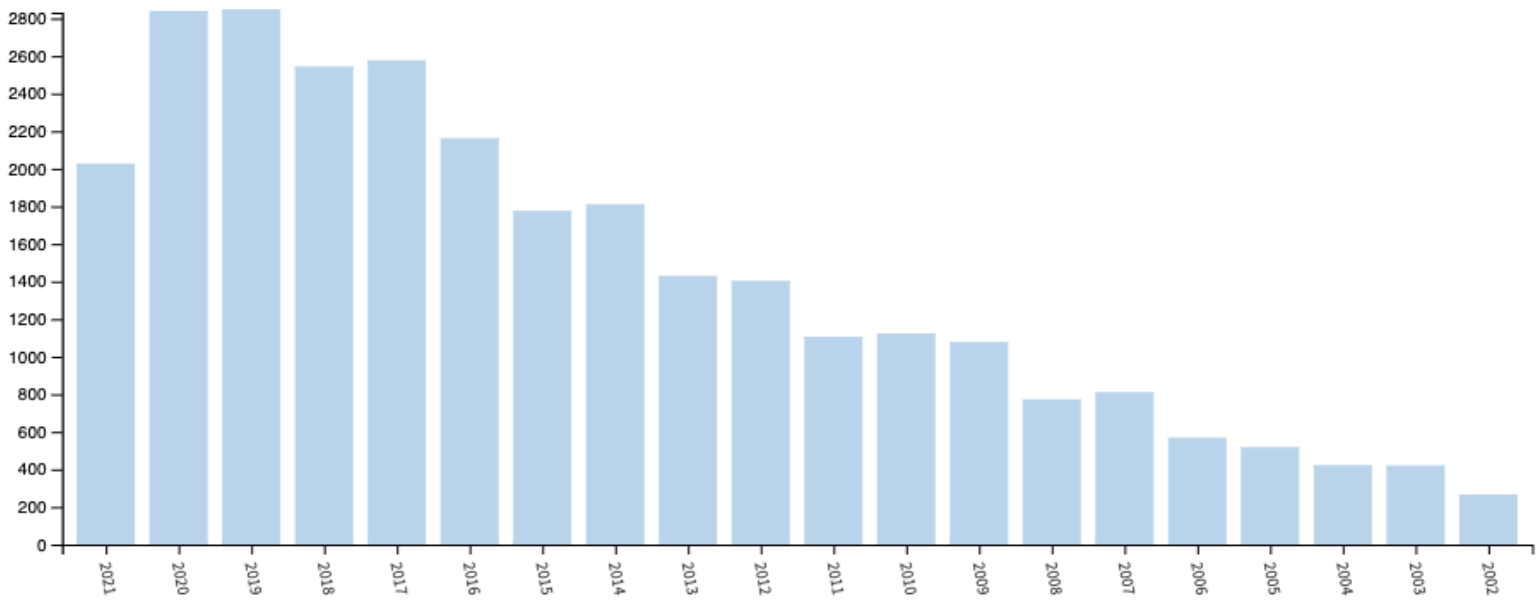

Figure 1.1 Distribution of publication frequency in the last 20 years for the topic "natural gas" [4] 
In order for the study to be as relevant as possible, several analyzes were performed for the period 2014-2021, for the topic "natural gas".

The subject "natural gas" results in a number of 18466 publications, of which 13922 are articles, 4055 are works of procedure, 862 are reviews, 243 book chapters, etc ..

Of the 18466 publications, between 2014-2021, for the subject "natural gas", most publications are in the category of Energy Fuels with 12514 publications (67.841\%), Chemical Engineering with 4381 (23.750\%), Thermodynamics with 4378 (18,855 \%), etc ..

Figure 1.2 shows that of the 18466 publications, the most active are the Chinese with 5160 publications (27.974\%), followed by Americans with 3167 (17,169\%), Iranians with 1239 (6.717\%), Italians, English, Canadians and Germans.

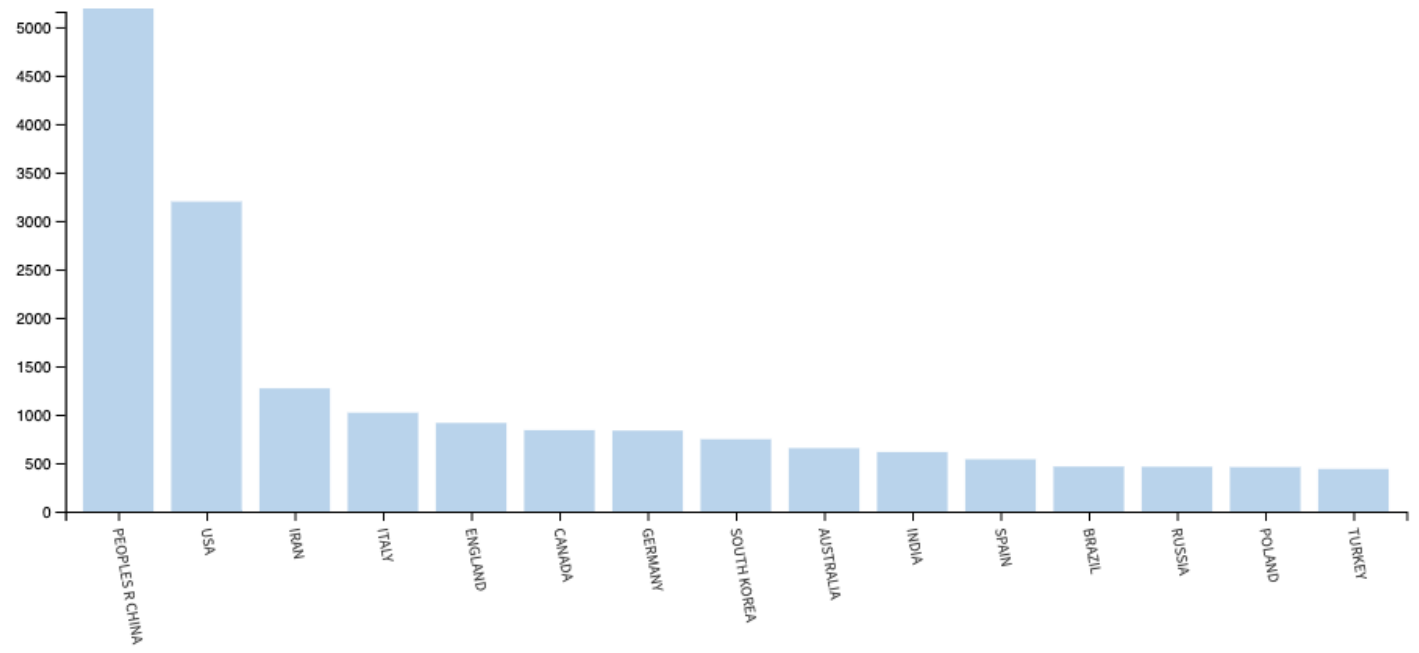

Figure 1.2 Distribution of publication by country for the topic "natural gas" [4]

Figure 1.3 shows that most publications are in journals and journals in which quality papers are published, such as Energy Procedia with 501 publications, AIP Conference Proceedings with 129 publications, IOP Concerence Series Earth and Enviromental Science with 127 publications, Computer Aided Chemical Engineering with 79 publications.

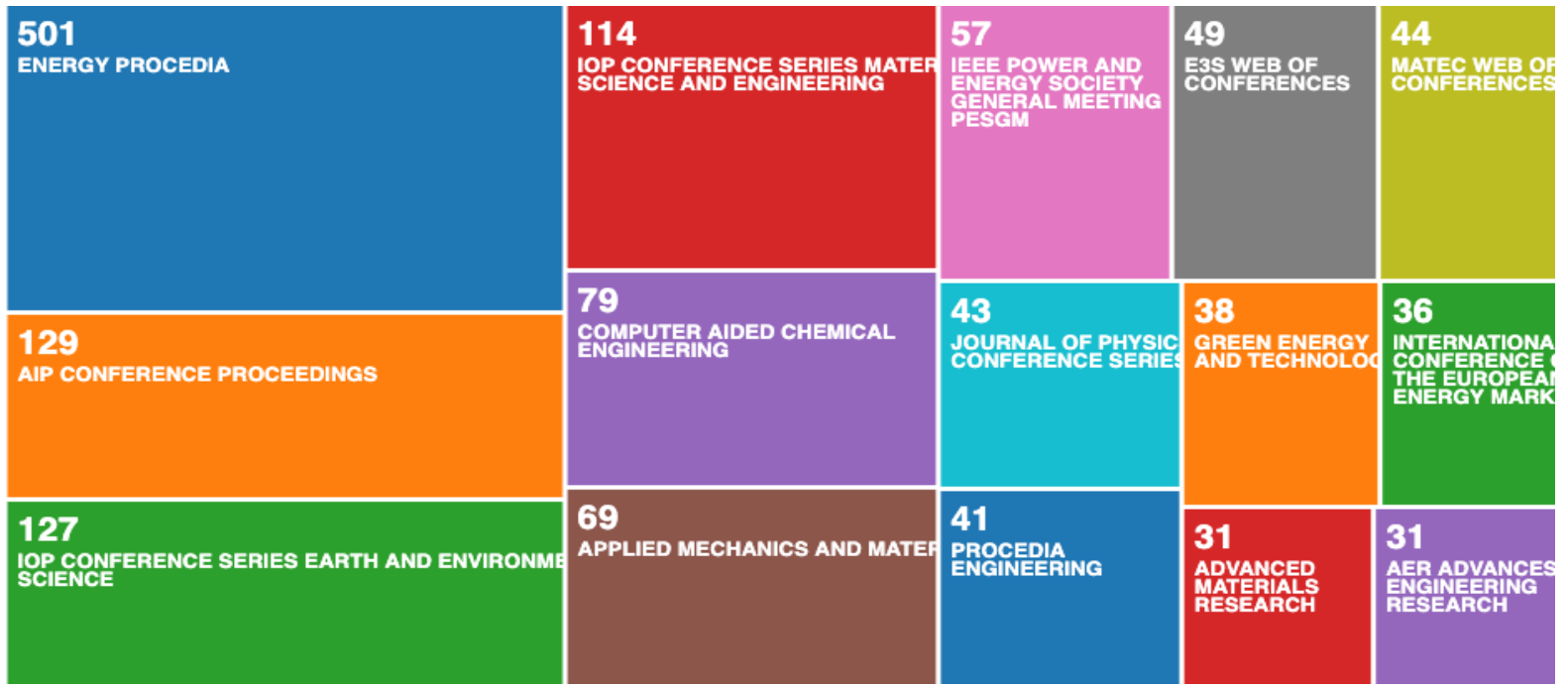

Figure 1.3 Distribution of publications in journals for the subject "natural gas" [4] 


\subsection{Data analysis from Web of Science with the VOSviewer software tool}

VOSviewer is a software tool with which you can build and view bibliometric networks. Bibliometric networks may contain journals, researchers or individual publications and may be constructed on the basis of citations, co-citations or relations of bibliographic co-citations and couplings. [5]

The Web of Science database was downloaded in files of 500 documents, complete papers, in Tab Delimited (Mac) format, which were imported into the VOSviewer software.

The authors who have published the most and have the greatest influence in the field of "natural gas" are Song Youngchen with 76 publications, 1888 citations and 268 links, Zhao Jiafel with 51 publications, 1550 citations and 198 links , Yang Mingjun with 47 publications, 1065 citations and 174 links, Li Xiao-Sen with 51 publications, 2134 citations and 152 links, as shown in Figure 1.4.

According to Figure 1.5, they started to publish significantly in 2016 and approached the subject of "natural gas" in more detail.

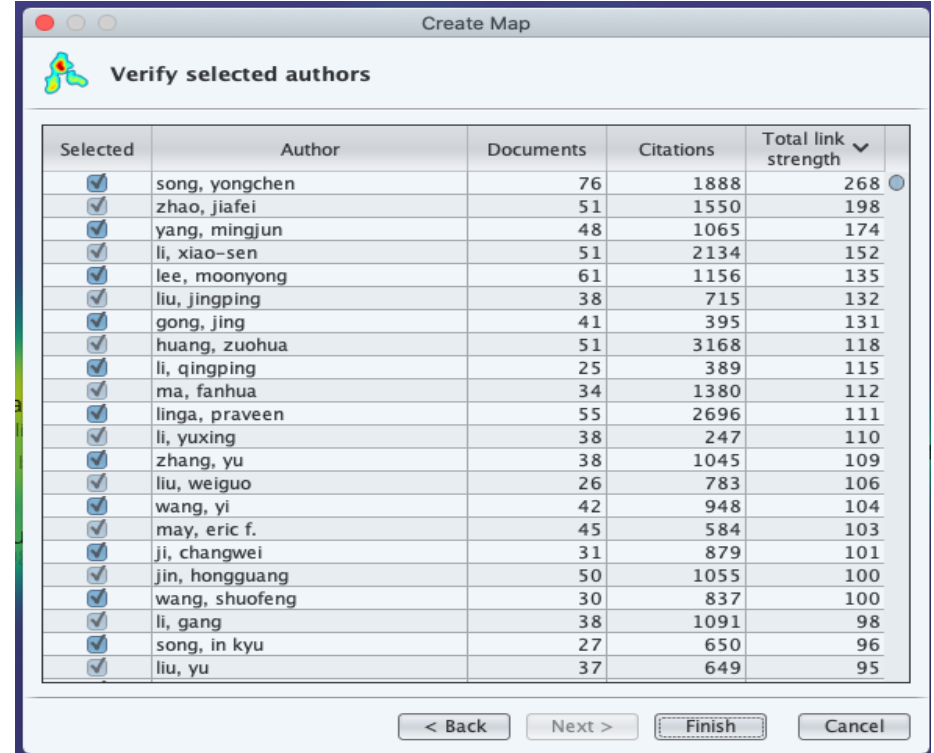

Figure 1.4 Authors with the most documents, quotes and strong links [5]

Analyzing Figure 1.6 we found that the terms with the greatest relevance for the searched field are natural gas, which is in the top, performance, optimization, methane, hydrogen, energy and model, and of the 5 clusters the most used is natural gas.

The most productive journals for the subject of "natural gas" are the Journal of Petroleum Science, Energy, Applied Energy, the Journal of Engineering for gas and the Journal of Natural Gas Science.

VOSviewer is an excellent tool to search, to find publications in the literature and to define the research direction, you can create bibliometric networks filtered by authors, countries, publications, keywords, citations and co-citations. 


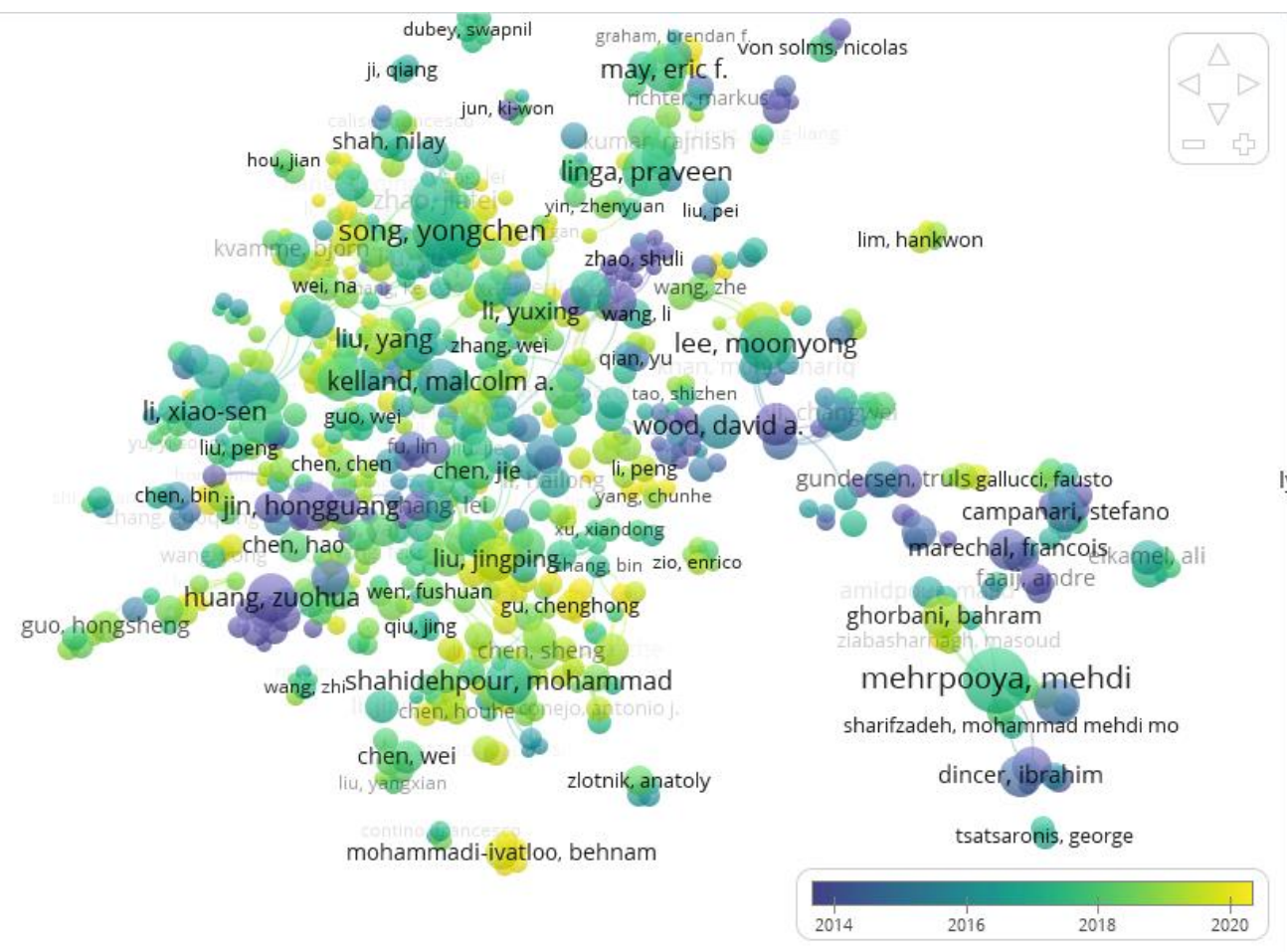

Figure 1.5 Authors by year of publication significant [5]

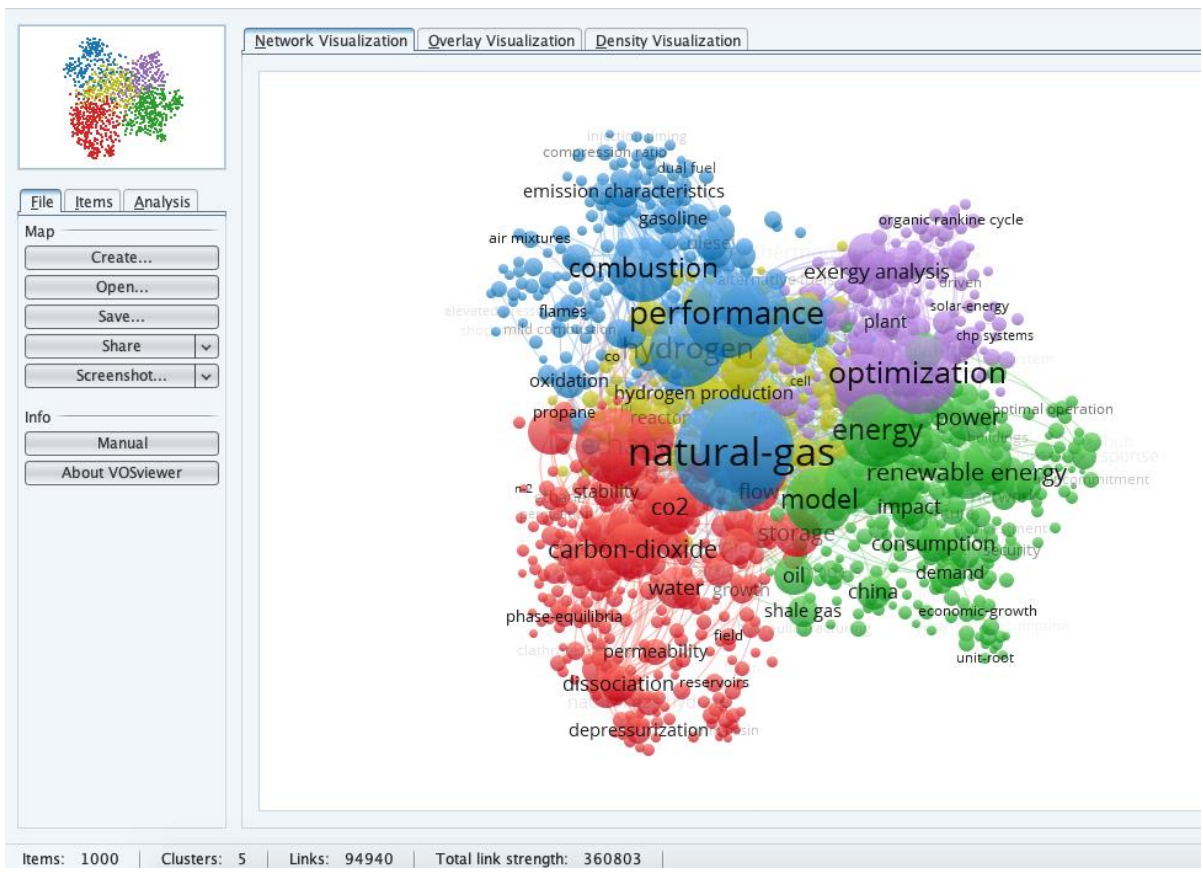

Figure 1.6 Keyword map [5] 


\subsection{Works in the field of "natural gas"}

The quantities of lost gas represent the difference between the quantity of gas delivered in the distribution system and the quantity of gas sold. [6]

More and more countries are recognizing the problem of unauthorized interventions on gas meters and trying to solve it. Authors from all over the world publish articles about gas meters and their optimization. [7]

Wang and Zhang propose the use of wireless technologies for gas meters to monitor and connect gas meters to the network. They are able to dynamically transmit data on gas consumption and flow. [8]

I believe that excessive digitization in this field is not so beneficial because such an advanced gas meter will have many technical problems and is very expensive to produce, which distribution operators do not want.

Roosnek proposes a new type of meter with ultrasonic measurement, which has a higher accuracy in measurement. [9]

Ultra-sound meters measure the amount of gas very accurately but their cost is enormous.

The next research direction is the DFMA analysis of the components in the meter in order to establish the correct production and assembly process of the meter in order to optimize costs and choose the best construction options.

\section{Design and improvement of a gas meter}

A gas meter has been designed that is affordable and can reduce or stop known methods of unauthorized intervention on measuring devices.

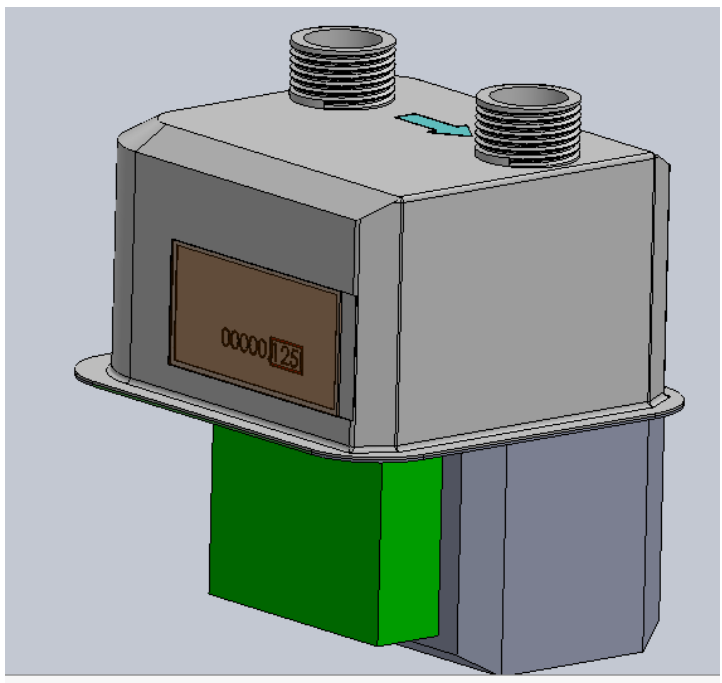

Figure 1.7 Gas meter prototype

A set of management procedures has been developed to define the construction of the gas meter, which mainly aims at safety in operation and the correct measurement of the amount of gas consumed. Product quality management, in this case the gas meter, is closely correlated with risk management, because a classic meter, built cheaply, does not have all the safety elements capable of preventing unauthorized interventions on the measuring device.

The meter is designed to have the integrator or recording mechanism embedded in the metal housing of the meter, so that any attempt to open the cover of the recording mechanism is eliminated.

This eliminates the possibility to intervene on the gear wheels or the possibility to change the actual index consumed.

The gear wheels of the counter are positioned and protected by a metal insert so that they cannot be stopped by foreign objects. 
The whole recording mechanism is made of plastic so that the actual measurement process cannot be influenced by the presence of magnets.

The gas inlet and outlet connections are interconnected inside the meter by two cables and a control mechanism that triggers a silent alarm if the gas meter is disassembled unauthorized. [10]

The alarm can be detected at the time of reading by the distribution operator or in real time with the help of GSM technology, depending on the chosen constructive variant. Additionally, a sieve can be mounted on each connection, input and output. If we have a damaged sieve, we have a sign that someone has dismantled the meter.

The meter can be read either manually, either by AMR technology, or by reading the gas meter in the immediate vicinity, by the technology of transmission through low frequency radio waves.

The meter is also equipped with a directional damper that prevents the gas from flowing in the opposite direction through the meter. Additionally, the meters can be equipped with temperature and pressure sensors for a more accurate measurement process. [11]

\section{Conclusions}

The Scientometric study in the Web of Science database is very helpful in determining your desired research directions.

VOSviewer helps you to get an overview of the field you are looking for, you can build your bibliometric networks and view them. The connections displayed in this software indicate to you the publications, magazines, researchers, the countries in which it was published, the interest for the field sought according to the years.

Natural gas consumption must be metered correctly and emphasize safety in operation. We can see the fragility of gas meters and the need to implement a healthy system of product quality and risk management procedures to prevent unauthorized interventions. The implementation of this meter would bring the following advantages: increased operational safety, reduction of unauthorized consumption and reduction of costs with personnel specialized in their detection.

\section{References}

[1] P. Kulaga., 2021. "Illegal gas consumption- general characteristics", Nafta- Gaz, nr. 4, s. 270278, DOI: $10.18668 /$ NG.2021.04.07

[2] Raport ANRE, "Raport privind rezultatele monitorizarii pietei de gaze naturale in luna Ianuarie 2021"

[3] ANRE, "Legea nr. 123 din 10 Iulie 2012 a energiei electrice si a gazelor naturale"

[4] Web of Science (Clarivate) - Web of Science Core Collection Basic Search.

[5] VOSviewer software- Visualizing scientific landscapes, https://www.vosviewer.com

[6] Gacek Z., Jaworski J., 2020. "Optimisation of measuring system construction in the context of high flow variability. Journal of Natural Gas Science and Engineering", 81: 103447. DOI: $10.1016 /$ j. jngse. 2020.103447

[7] Botev L., Johnson P., 2020. "Applications of statistical process control in the management of unaccounted for gas. Journal of Natural Gas Science and Engineering", 76: 103194. DOI: $10.1016 /$ j. jngse.2020.103194.

[8] Wang J., Zhang W.Y., 2013. "A New Method to Prevent Stealing Gas in a Natural Gas Supply System. Petroleum Science and Technology", 31(20): 2065-2073. DOI: 10.1080/10916466.2011.561263

[9] Roosnek N., 2000. "Noveñ digital signal proccesing techniques for ultrasonic gas flow measurement", Volume 11, Issue 2, pp. 89-99

[10] Ilea P., Săvescu D., Stoica A., 2020. "Aspects regarding the management of a natural gas measuring device". RMEE 2020

[11] Ilea P., Săvescu D., Stoica A., 2018. "Some aspects of quality and risk management for natural gas meters". PRASIC 2018 